Why can't someone stay with me between six and nine?

We could watch the video together or talk of happier times. And I wouldn't have to be Alone with my impending death invading my mind.

Where has all the compassion gone?

Don't they know that stress is a big killer?

Even healthy people have need of Human touch.

Why is "Not to be alone" asking for too much?

I'm not requesting a visitor to jump under the covers, Exempting one beautiful safe encounter.

For me there will be no other.

\title{
STAY STRONG THEY SAY
}

Patrice O'Donnell

Stay strong they say, feel the loneliness I feel.

Take it one day at a time, smile, accept the fact you're dying...stay strong they say.

Play hard, pay hard, pay your dues.

Hey! You chose to use...

Stay strong they say.

Society such as it is will pay to put you in the ground.

Where's society's compassion whilst you're still around...

stay strong they say.

Due to anti-social behaviour, housing turned me down

Didn't I already do my time?

To want a little place to live, is that such a crime?

Stay strong they say.

Have you any idea the risk you take, when you share the syringe?

Momentary gratification...H.I.V. the result of the binge...

Stay strong they say.

I know you hear me but you're not listening.

So maybe you'll be next to take my place...in search of meaning.

As it gets harder to hide the pain on your face...

Stay strong they say.

I won't let society put me in an early grave,

As long as there' a breath left in me,

Maybe there's someone I can save...

Stay strong they say.

Watch Me!

* Patrice O'Donnell died December 8, 1990 in Kingston General Hospital where she was taken by ambulance from Prison for Women.

(Reprinted Courtesy of Tightwire Spring, 1991, pp.8-10) 